\title{
Smart City- Far and Near Dream in Indian Context
}

\author{
Aishwarya N., PhD \\ Christ Deemed to be University \\ Bannerghatta Road Campus \\ Bangalore, India
}

\author{
Aarthy Chellasamy, PhD \\ Christ Deemed to be University \\ Bannerghatta Road Campus \\ Bangalore, India
}

\author{
Shikha Bhagat, PhD \\ Christ Deemed to be University \\ Bannerghatta Road Campus \\ Bangalore, India
}

\begin{abstract}
Information and Communication Technology (ICT) brings a notable change in the way a government initiates and frames policy making. The concept of Smart City (SC) means to improve the quality of life of people and there is no universally accepted definition of smart city as it differs country to country and state to state. On analyzing the literature the authors has identified four impeding factors(urbanization, government support, social support and Technology) and three facilitating factors (e-governance, sustainability and infrastructure) for the development of smart cities in Indian context. The authors has emphasized on six important components (Smart governance, Smart technology, Smart energy, Smart education, Smart infrastructure, Smart Mobility) which the policy makers can concentrate to achieve the dream of Smart Cities in India. There are also private firms like IBM, Gaia, Cubical Labs, FluxGen Technologies, Altiux Innovations SenseGiz and CISCO. CRISIL, KPMG, McKinsey and Matt McDonald which actively contributes for the Smart City Initiative in India. This work gives an idea for policy makers and managers of the company to improvise on the smart city strategy and planning for better implementation to compete in twenty first century.
\end{abstract}

\section{General Terms}

Your general terms must be any term which can be used for general classification of the submitted material such as Pattern Recognition, Security, Algorithms et. al.

\section{Keywords}

ICT, Infrastructure, Policy making, Private firms, Smart city, Urbanization

\section{INTRODUCTION}

The 19th century was a century of empires, the 20th century was a century of nation states. The 21 st century will be a century of cities."- Wellington E. Webb

In recent times there has been an increasing interest in the concept of the smart city by policymakers across the globe. A decade ago the number of cities with more than 1 million population was countable but today the count has amplified to 480 and can foresee more growth in future [1]. Information and communication technologies (ICT), act as a force for urban development and also changes the way a city can compete in which municipalities take greater responsibility to represent their best framework for urban development [2]. In today's scenario, international competitiveness is driven by the innovativeness of the city and that's the reason cities are undergoing a massive transformation paving way for new industrial clusters and small towns being transformed into metropolitan. United Nations Department of Economic and Social Affairs (UN DESA) stated that $55 \%$ of world population lives in urban area and is expected to increase to $68 \%$ by 2050 and the $90 \%$ of this increase takes place in Asia and Africa. UN DESA also projected that urban population is going to be densely concentrated in countries like India, China, Nigeria and India may constitute 416 million urban dwellers by 2050 . Due to this escalating population government should figure out the ways of creating future space for its people. City administrations must prioritize the core activities, what to add, and shed for better prospects of its people. [4] said that in India (2019), roughly $1 / 3$ rd of the total population resided in cities and the inclination (Fig.1) shows a swell of urbanization by $4 \%$ in the last decade, which indicates that migration is more towards urban to find work and make living in the cities. This migration poses the biggest challenge managing the livability of India's urban spaces.

India may set back in the development of urban infrastructure because of complex political and leadership structures, gaps in capability building, shortfalls in funding, waste disposal, disaster management which shows a fall in quality of life for many of its citizens. This urbanization wave that is extensive across India represents country's greatest opportunities and most challenging factor. This becomes a predominant reason for India to devise an efficient and sustainable solutions for servicing urban areas reaping the benefits by embedding technology to learn from other parts of the world. Thus India too is in the race of building smart cities with world-class selfsustainable habitats with minimal pollution levels, maximum recycling, optimized energy supplies and efficient public transportation [5].

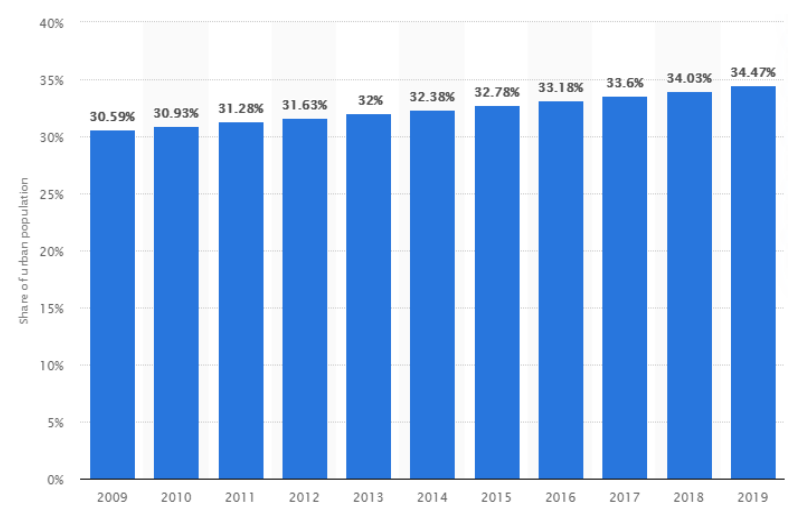

Fig.1 India Degree of Urbanization from 2009 to2019 Source: Statista.com

\subsection{What is a Smart City?}

There is no universally accepted definition for smart city and it varies from county to country and city-city depending on the level of growth, willingness to adapt, available resources, and desire of citizens for the change. Prime Minister Narendra Modi launched the project "Smart Cities" on 25th June 2015. Regarding this, three existing cities from each state should be selected under Smart City Mission which indicated a shift in Mission's focus from Greenfield to Brown-field development which mean that instead of building "100 new smart cities" 
mission is to "making existing cities smart" [6]. So the Government of India has decided to develop 100 smart cities by 2024 and the MoUD is given responsibility to implement smart city missions in collaboration with respective cities. This is a five-year program where the central and state government together release the funds for the development of city from a time period of 2017-2022 and the mission will start showing its results from 2022 onwards [5]. The concept of building Smart city revolves around three major aspects as in Fig.2.

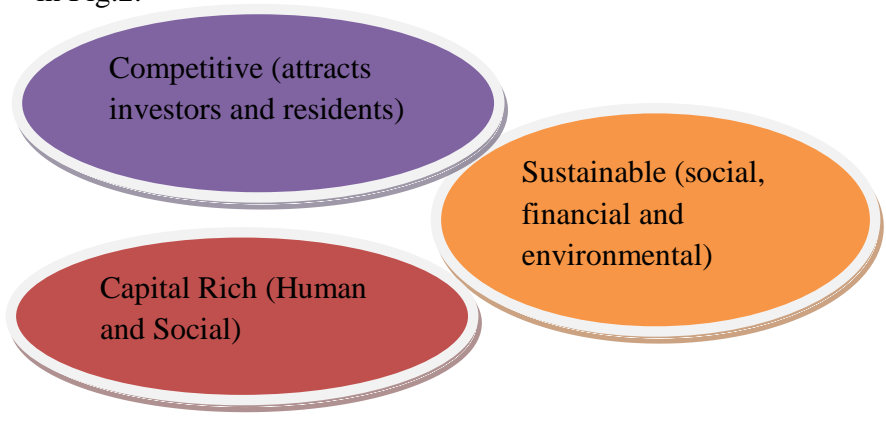

Fig.2 Key Aspects of Smart Cities

Source: Authors Perception

The strategic components or the proposal submitted by the shortlisted city should touch upon City Improvement (retrofitting), Redevelopment, Greenfield development, and pan-city development models. City improvement focus on enhancing existing area efficient and livable expecting intensive infrastructure packed with high-end applications in modernized smart city. The redevelopment will have an impact on the current built-up space and facilitate the inception of new layout with improved infrastructure utilizing blended land and with expanded density. City extension or Greenfield development implements smart solutions in a previously vacant area using innovative planning with provision for affordable housing especially for poor. Pan city development foresee the application of selected smart solution (intelligence traffic management system) in the city by using technology, information and data to make services better [7].

\section{CONCEPTUALIZING SMART CITY CONCEPTS}

Though every one of us could have come across the buzz word "Smart City", still there is no clear and reliable information on the concept [14], [10], [18]. Smart city is to lead a sheltered life with a better environment and wellorganized urban center with advanced infrastructures including sensors, electronic gadgets, networks to stimulate economic growth aiming high quality of life [2], [8], [9] with citizens involvement and governmental efficiency [10]. Another literature [6] categorizes 'smart city' definition into three major divisions first one being Research and Academic view which ranks sustainability as primary followed by quality of life and emergence of economy as secondary and tertiary factors. Second division Corporate view looks at ICT as one universal solution where other factors may fall in line using digital technologies [11]. The third division Government sector reflects the usage of ICT in governance, relevance of human resources and stress on quality of life and environment. Any city can become a new silicon valley if it tries to create a global network with highly integrated economic centers connected by massive networks of airports, highways or to the build so-called "intellectual city" with advanced ICT [12], [13]. [14] stated that building a smart city is a tactic to reduce the problems caused by rising urban population and urbanization. [15] proposed an assumption that wider availability of information will motivate creation of urban system models and the ICT may fetch a number of benefits such as reduced usages of energy and water, carbondi-oxide emission and betterment in usage of infrastructure.

[16], said that a smart city is usage of Smart computing to deliver its core services to the public in an efficient manner. Smart computing will have a vast industry focus like city administration, education, health care, transportation, and utilities. Cities become a center point of attraction and an influential part in the development and growth of a nation. The smart cities concept relies on two fast-forwarding factors one is global urbanization and the second one is digital transformation through Industry 4.0. These trends have chances of improving human life more comfortable in an environmentally sustainable and inclusive manner (Ministry of Housing and Urban Affairs). The steep rise in urban population will amplify the demand for resources, mobility, and other urban services in cities. So, cities have to become smarter in terms of urban services. [19], defines smart city as, a city connecting physical, social, and business components to influence the communal intelligence of the city. [20] states that smart city is a reflection of the modernistic approach considering issues like flexibility, transformability, individuality and synergy. [21] define smart city as standardized, interface that enhance intellectual aspects. Standardization denotes the procedure to capture and integrate live real-world data with the help of sensors, kiosks, meters, smart devices, and data acquisition system like human sensors. Interface refers to the integration of data into an enterprise computing platforms and communication among various information systems. Intelligence is a process of including analytics and modeling, visualization to leverage business process and operational decisions. Natural Resources Defense Council defines smart city as more efficient, sustainable, equitable and livable. A report by McKinsey [23] stated that as urbanization multiply, technology will be the option to address environmental issues which might cut down emissions by $10-15 \%$, water consumption may reduce by 20 $30 \%$ and solid waste reduction by $10-20 \%$. Thus keeping in mind the exponential growth of urban population and enhanced service quality in India, policymakers and researchers should have deeper insight and understanding about information related to smart city development and barriers related to it. Building a smart city is not an easy task in a country like India because of its huge population and also the success depends on the holistic presence of residents, entrepreneurs and visitors becoming actively engaged in saving energy and implementing new technologies.

\section{IMPEDING FACTORS FACED BY INDIAN SMART CITIES 3.1. Migration of Population-Rapid Urbanization}

The evolution of industrialization brings the gap between rural and urban areas with a notable shift of workforce. The migration process is influenced by factors like social, cultural, economical with varying outcomes depending on the location. Thus India experiencing a steady growth in the urban population with the emergence of new cities and towns [24], [25].

\subsection{Lack of Government Support}

Lack of coordination between city's operational nodes [26], [27] and there might not be clarity in the vision of how IT can 
be used for city development [14]. Political instability also plays an important role related to implementing smart city and when a government is not stable it may lead to reduced hope and trust by people on government for the betterment of living [27] [28] [33].

\subsection{Lack of Social Support}

No city can be smart until the citizens have the aspirations to dwell on it. The citizens should be encouraged to submit and evaluate their ideas for innovation in smart city design [29], [27], [30]. There might be a lack of awareness among the public about smart city and quality of life reaped out it [30], [27]. [31] and [32] stated that inequality in citizen's education, income levels and skills may also hinder the smart cities' development [33].

\subsection{Lack of Technology Support}

ICT are key drivers of smart city initiative and integration of this ICT with development projects can change the city [10], [35] with enhanced opportunities and management function [36]. A city cannot be smart without implementing technology aspects. Lack of implementation of technology might be because of less awareness among policymakers and planners about usage and knowledge of right and modern digital technology for the smart city development [34],[14], [32].

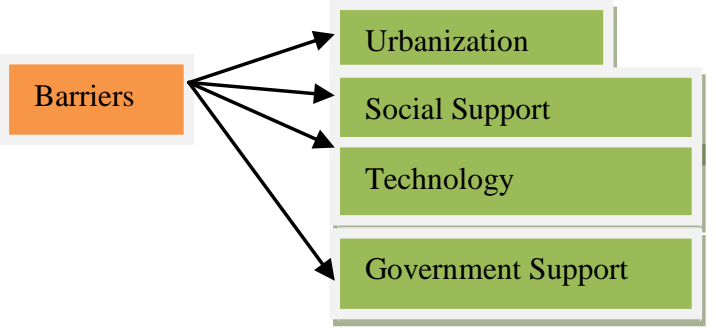

Fig.3. Impeding Factors for Smart City Development Source: Authors Perception

\section{FACILITATING FACTORS FOR SMART CITY DEVELOPMENT}

The constant increase of population in cities of developing and developed countries and a parallel increase of technology has motivated local governments to meet the demand of citizens with available technology to build smart cities. Johnson Controls an Ireland based company conducted its Smart City Indicator survey in 2018 over 12 countries including India, China, USA, Canada, Mexico, Brazil, France, Germany, Poland, Argentina, Colombia and Singapore. The survey revealed three interesting driving forces- economic development, environmental pollution and sustainability and this may have variations according to local country needs. [14] stated that management and organizational initiatives should be discussed on e-governance aspects as a major key driving factor in smart city initiative. In this context, [38] discussed that smart city initiative is majorly driven by government schemes with the usage of ICT tools to serve citizens better. [39] has found out that stakeholders relation is an important success factor in the process of smart city development. A report by [40] envisaged that Smart City 2.0 will be shifting of focus from connecting infrastructures to engaging governments, citizens and businesses with 3 driving factors as quality of life, economic competitiveness and environmental consciousness. Many authors have suggested sustainability as a driving agent since it deals with the efficient management of natural resources to enhance the quality of life of society for present and future generations [10], [41], [42]. [43] from their study suggested drivers like urban planning, city infrastructure, mobility, public safety, health, sustainability, and public policies require a comprehensive vision focus on the prime concern of society.

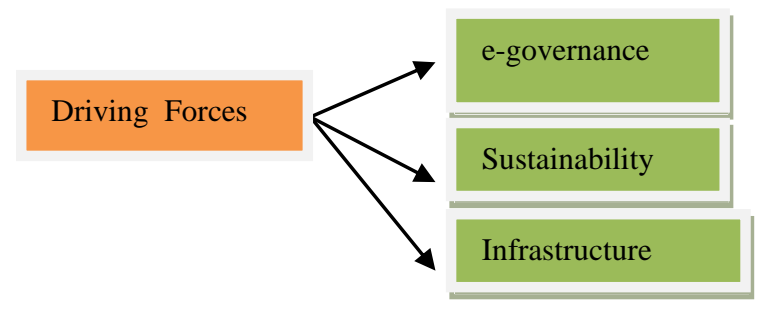

Fig.4 Facilitating Factors For Smart City Source: Authors Perception

\section{SMART CITY COMPONENTS 5.1 De-Coding the Smart City}

Smart cities herald a new era. Using technology in reshaping the traditional infrastructure for building roads, bridges and buildings form a seamless infrastructure. Various sensors, wireless capabilities and new technologies are used to harness the benefits of data analytics and improvise a city's carbon footprint, efficiency and the quality of life for its citizens. The Smart city approach adopted by the government of India has four major pillars, namely social infrastructure, physical infrastructure, institutional infrastructure and economic infrastructure [46]. For a developing country like India, the dream of building smart cities needs a paradigm shift from the ground up. The need for state of the art technology, consultancy, expert guidance and the like becomes imperative which raises a lot of opportunities for both public as well as private organizations. Investments in the social, institutional, economic and physical infrastructure act as hallmarks of the city [48]. The important components for building a smart city in Indian context are as follows.

\subsection{Smart Governance}

It includes the smart use of e-government services and citizenship services. It improves public policymaking and decision making with the help of ICT and excludes external agents. With respect to India, US\$1.2 billion is allocated for smart cities and FDI norms are relaxed. US\$83 million is allocated for the Digital India Initiative and the PPP Model to be used is to upgrade infrastructure in 500 urban areas. The government expects the Smart City projects to create 10 $15 \%$ rise in employment. [44].

\subsection{Smart Technology}

Smart city technologies are being developed to address a range of issues, including energy management, water management, urban mobility, street lighting, and public safety. These innovations are underpinned by general developments in areas such as wireless communications, sensor networks, data analytics, and cloud computing. Broadband Penetration rate of over 80 percent is a target for implementing smart technology and equipping users with smart personal devices as well [47].

\subsection{Smart Mobility}

Smart mobility ensures sustainable, innovative and safe transport systems. It improves the operational efficiency in road management through real-time data collection, vehicle information, linking traffic-related data, and RFID toll collection technology. It also aids in smart parking, intelligent 
traffic management and integrated model transport [44]. A range of smart technologies has transformed geo-location tracking to a situation where the monitoring of location is pervasive, continuous, automatic and relatively cheap and easy to construct travel related information. Also, sensor networks have been deployed across streets such as bins and lampposts to analyze and track phone identifiers [51]. The government of India has set ambitious targets for public transportation for supporting its massive population. By 2027, Electric vehicle charging stations in all urban areas and all state and national highways are to be introduced. The Ministry of Urban Development plans to invest more than US\$20 billion on metro rail projects in the coming years [44].

\subsection{Smart Infrastructure and buildings}

The designs created by smart infrastructure will be used in building efficient communities that can grow their own food and manage flood water systems as well. Sensors and technological embedded controls monitor existing conditions and provide real-time feedback in case modifications are needed. Smart buildings make occupants productive with good air, sanitation, light, security and much more. Smart water management includes systems such as smart meters, leakage identification and prevention and water quality monitoring [44]. Many smart buildings use smart card tracking, installed with barcodes or RFID chips to gain access over different parts of the building [51]. Under the flagship "Safe City" project, the Union Ministry of India proposed US\$333 million to make seven big cities (Delhi, Mumbai, Kolkata, Chennai, Ahmadabad, Bangalore and Hyderabad) to focus on technological advancement rather than manpower Disaster Management [44]Bajaj

\subsection{Smart Education}

An important element in smart cities is having well-educated citizens who can be proactive and bring changes to the advancement of new technologies. Designing digital development plans closes the digital divide in classrooms and empowers the newer generation with digital skills. Smart education also enables an affinity for lifelong learning and cosmopolitanism.

\subsection{Smart Energy}

The main problem of cities in view of the transition to the concept of smart cities is pollution and covering the electricity needs for all inhabitants [45]. Renewable energy is the new future, and it is wise to move to a model based on the principles of smart power generation, smart power grids, smart storage, and smart consumption. The application of smart grid has led to a number of technologies for the housing industry. Advanced Metering Infrastructure and Home Area Networks are the two new technologies that have a direct effect on the operations of a home. These technologies have influenced many new products and applications for homes; examples include smart meters, car-charging stations, smart thermostats, renewable-energy installations, and smart appliances [55]. The plans regarding smart grid in India is, Implementation of 8 smart grid pilot projects with an investment of US\$10 million, adding at least $250400 \mathrm{GW}$ of new power generation capacity by 2030 and to install 130 million smart meters by 2021 [44]). Patterns can be derived based on the data from each smart device used against every object and piece of infrastructure available. This can help build the Smart city's next-generation products in real-time [53].

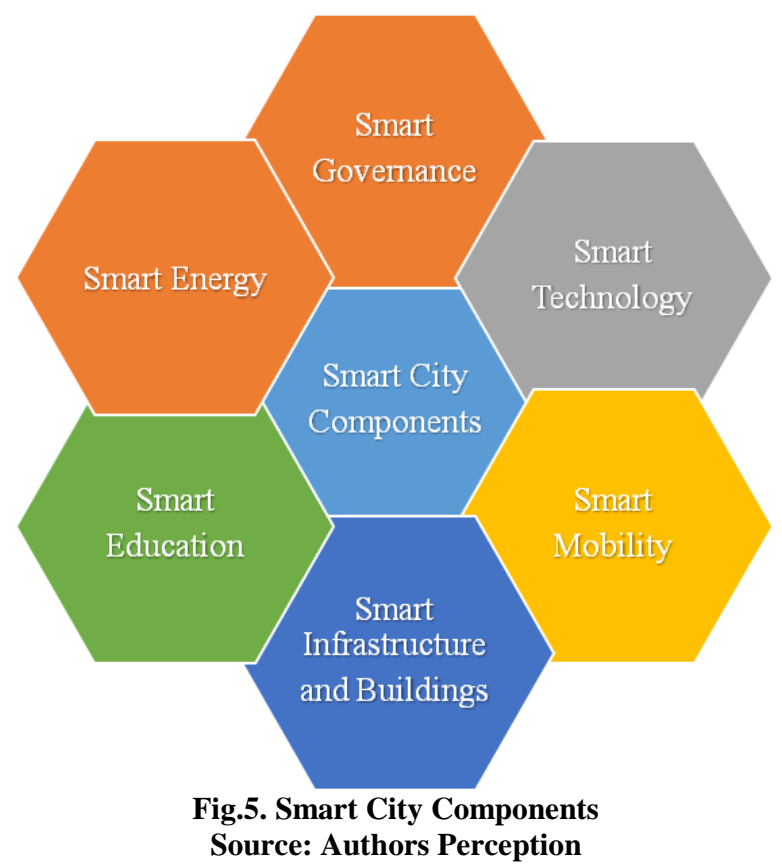

\section{COMPANIES ASSOCIATED WITH SMART CITY}

The global Smart cities market was accounted for US\$ 773.19 Billion in 2016 and is expected to grow during the forecast period 2017 - 2025, to account for US\$ 3651.49 Billion in 2025 [52]. Key trend which will predominantly affect the market in the coming year is smart cities market consolidation due to growing competition. Furthermore, the market is anticipated to witness significant growth owing to the increasing urbanization. The Companies proactively participating in global market are ABB Ltd, Accenture, Cisco, Ericsson, Schneider Electric, GE, Microsoft, IBM Corporation, Oracle and Siemens among others. There are a bunch of IT companies involved in the development of smart cities worldwide from 2006, IBM's 'Smarter planet', Cisco's 'Smart+ connected community', Siemens's "citycockpit', Microsoft's 'CityNext' Programme is among the few[57].

In India, some of the popular companies in this space are IBM, Gaia, Cubical Labs, FluxGen Technologies, Altiux Innovations SenseGiz and CISCO. CRISIL, KPMG, McKinsey and Matt McDonald are among the 37 consulting firms which have been given the responsibility for preparing action plans for the proposed smart cities in India [56].

Gandhinagar, the capital of Gujarat is said to be the first smart city of India build on the banks of river Sabarmati. Another epic initiative taken by the WAVE group is in the city of Ghaziabad. By living to its 'Smartness' name, the city uses smart pumps that ensure minimal waste wastage and $\mathrm{pH}$ meters to ensure water quality. Smart traffic signals are equipped to ensure the smooth flow of traffic in the city and parking lot sensors are installed to enable an effective parking management system. Apart from this, Smart gas and Smart surveillance systems are fitted to give a complete digital infrastructure to the smart city concept.

Gaia is the leading IoT startups in India which works in areas such as sensing, tracking, metering, and analytics, where it feeds real-time data streaming and data insights on assets, particularly their consumption and performance. Gaia is at the helm of e-governance for the Swachh Bharat Mission, and 
supporting the Delhi government as well with its smart water metering solution. Gaia has worked on many ICT designs, such as the Delhi-Mumbai Industrial Corridor, Kashi Smart City Challenge plan, and Kalinganagar Tata Steel Township, to name a few for the Smart city project [50]. For Smart cities to thrive and be successful, they need to look beyond a specific set of technologies or desires of related industries. All trending technologies such as Artificial Intelligence, Block chain, Internet of Things and others are interconnected. Hence organizations working on this space need to converge at some point to create the trusted digital infrastructure. Figure shows the convergence of market competition at various arena where organizations are creating a digital ecosystem in the smart city space.

The current status update of Smart cities in India shows that, of 5151 projects initiated, only 3629 have been actively pursued and are under progress and about 25 percent of the projects are completed. Reports show that only three-fourth of the funding has been released between the year 2015-2019 and around 36 percent of funds have been underutilized. Of the 100 cities announced under the Smart city project, Delhi, and cities in Gujarat and Madhya Pradesh have better completion rate than others [58]

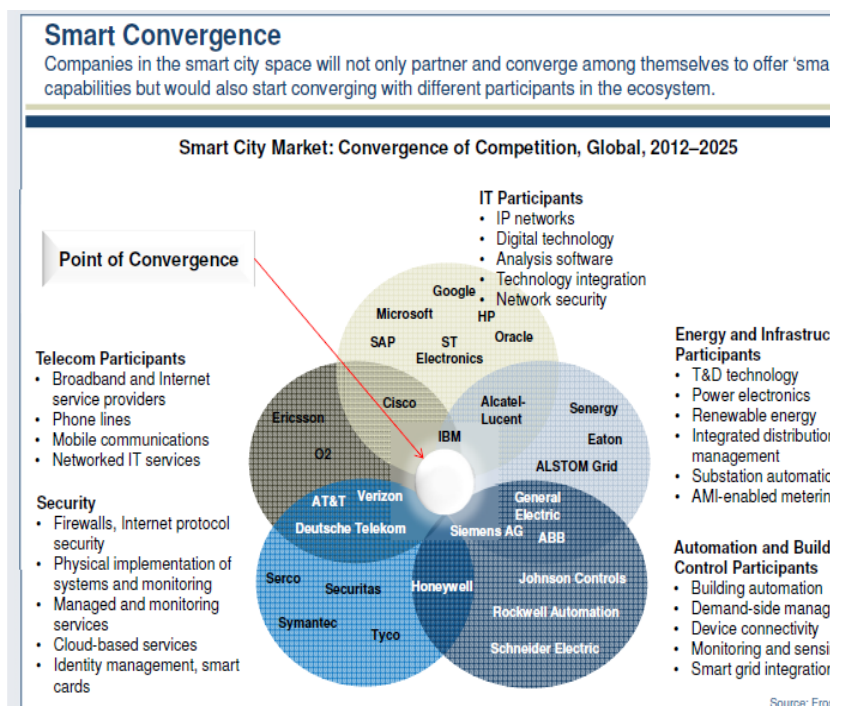

Figure 6. Smart City Market: Convergence of Organization's Competition Source: Frost and Sullivan Report

\section{CONCLUSION}

The concept of Smart City envisioned by the current Government is a much needed and timely one. Today, the smart city concept is viewed as a vision, manifesto or promise aiming to constitute the twenty-first century's sustainable and ideal city form. However, there are numerous ethical issues associated with the deployment of technologies used in smart cities. Government needs to be careful enough in creating smart cities with ethics and privacy as the core principles. Building smart cities are more of a process than an end goal and it is continuously evolving in real time and transforming based on the needs and requirements. Building the brand of 'Smart city' promotes prestige and attractiveness to a nation and promises a lucrative industry with a huge potential of growth and revenue. In India, transforming the existing crowded cities into smart cities is a daunting task. While Greenfield cities as planned along the Delhi-Mumbai corridor are a little easier to set up, conceptualization and implementation of the same have to be done with a forward vision and continuous monitoring in existing cities. The concept of Smart Cities in India is an evolving one and therefore, a great deal, as stated above, will depend upon proper formulation and careful implementation.

\section{FUTURE SCOPE}

With half of the mankind living in modern cities equipped with smart parking, smart traffic control, water management system and others, smart cities have a tighter role in combating against the many challenges posed by rapid urbanization. Over a time, IoT and other advanced technological solutions will be implemented to make the cities easier to live in and save costs. It further provides opportunities for Public Private Partnership and ensures revenue generation, cost reduction, operational efficiency and improvement in the overall customer value and experiences. Existing mobile networks such as 3G/4G may not be sufficient to handle the advanced technologies needed for building a smart city, hence $5 \mathrm{G}$ technology may be introduced and be implemented at a larger scale for efficiency and effectiveness [54]. However, the process of a smart city transformation journey does not happen overnight. The government needs to concentrate on solving the issues pertinent with modern cities and focus on building a long term goal to achieve efficiency in the process. The amalgamation of big data with other developing technologies will fundamentally lead to the creation of smart cities. Modern cities need ample amounts of time and money to incorporate these technologies and techniques to become smarter. However, while technology acts as a key stimulant for what makes a city 'Smart' like sensors, data analytics, geotagging and the like, technology is not an end to itself, the bigger picture is more about serving the needs of various stakeholders in the community.

\section{REFERENCES}

[1] Palmisano, Samuel J. Shining Cities on a Smarter Planet. The Huffington Post. May 22, 2009. http://www.huffingtonpost. com/sam-palmisano/shiningcities-on-asmart_b_206702.html.

[2] Tuba Bakıc1, Esteve Almirall and Jonathan Wareham (2013). A Smart City Initiative: the Case of Barcelona, Journal of Knowledge Economy, 4,135-148.

[3] United Nations, Department of Economic and Social Affairs, Population Division (2019). World Urbanization Prospects: The 2018 Revision (ST/ESA/SER.A/420). New York: United Nations.

[4] H.Plecher (2020). India: Degree of Urbanization form 2009-2019. July8,2020. https://www.statista.com/statistics/271312/urbanizationin-india/

[5] SESEI (2018), http://www.sesei.eu/wpcontent/uploads/2018/08/Report on-Smart-CitiesMission-in-India_July_2018_Final.pdf

[6] Bhattacharya, S., and Rathi, S.(2015). Reconceptualizing Smart Cities: A Reference Framework for India, (CSTEP-Report-2015-03).

[7] http://smartcities.gov.in/content/innerpage/strategy.php

[8] Caragliu A, Bo C, Nijkamp P (2009) Smart cities in Europe. Research memorandum, 48. Retrieved from: http://www.intaaivn.org/images/cc/Urbanism/backgroun d\%20documents/01_03_Nijkamp.pdf 
[9] Hall RE (2000) The vision of a smart city. (Brookhaven National Laboratory, USA), 2nd International Life Extension Technology Workshop, Paris, 28 September.

[10] Hollands RG (2008) Will the real smart city please stand up? City 12(3):303-320

[11] Batty, M., Axhausen, K. W., Giannotti, F., Pozdnoukhov, A., Bazzani, A., Wachowicz, M., Portugali, Y. (2012). Smart cities of the future. The European Physical Journal, 481-518.

[12] Harris, P. H. (1992). The Techno-polis phenomenonsmart cities, fast systems, global networks. Behavioral Science, Vol. 38.

[13] Natalia veselitskaya, Oleg karasev and Alexey beloshitskiy (2019).Drivers and Barriers for Smart Cities Development. Theoretical and Empirical Researches in Urban Management, Vol. 14, No. 1. 85-110.

[14] Chourabi, H., Nam, T., Walker, S., Gil-Garcia, J. R., Mellouli, S., Nahon, K., Pardo, T. A., \& Scholl, H. J. (2012). Understanding smart cities: An integrative framework. In Proceedings of the 45th Annual Hawaii International Conference on System Sciences, HICSS-45, pp. 2289-2297.

[15] Harrison, I., Donnelly, A. (2011). A Theory of Smart Cities. IBM Working Paper.

[16] Doug Washburn and Usman Sindhu (2010). Helping CIOs Understand "Smart City" Initiatives Defining The Smart City, Its Drivers, And The Role of The CIO. Forrester Research, Inc. February 11,2010.

[17] Data Smart Cities: Empowering Cities through Data (2018). Retrieved from: https://online.ndmc.gov.in/msikc/learning_materials.asp.

[18] Boulton, A., Brunn, S.D., \& Devriendt, L. (2011). Cyber Infrastructures and "smart" world cities: Physical, human, and soft infrastructures. In Taylor, P., Derudder, B., Hoyler, M., \& Witlox, F. (Eds.),International Handbook of Globalization and World Cities. Cheltenham, UK: Edward Elgar.

[19] Hall, R. E. (2000). The vision of a smart city. In Proceedings of the 2nd International Life Extension Technology Workshop, Paris, France, September 28. Available from: http://www.osti.gov/bridge/servlets/purl/773961oyxp82/webviewable/773961.pdf.

[20] Giffinger, R., Fertner, C., Kramar, H., Kalasek, R., Pichler-Milanović, N., \& Meijers, E. (2007). Smart Cities: Ranking of European Medium-Sized Cities. Vienna, Austria: Centre of Regional Science (SRF), Vienna University of Technology.

[21] Harrison, C., Eckman, B., Hamilton, R., Hartswick, P., Kalagnanam, J., Paraszczak, J., \& Williams, P. (2010). Foundations for Smarter Cities. IBM Journal of Research and Development, 54(4).

[22] Natural Resources Defense Council. What are smarter cities?, Retrieved from http://smartercities.nrdc.org/about.

[23] Jonathan Woetzel, Jaana Remes,Brodie Boland, Katrina Lv, Suveer Sinha,Gernot Strube,John Means,Jonathan Law, Andres Cadena, Valerie von der Tann (2018). Smart cities:Digital solutions for A more Livable Future
(2018):

Retrieved

from: https://www.mckinsey.com/ /media/McKinsey/Industrie s/CapitalProjects/Infrastructure/Our Insights/Smart cities/Digital solutions for a more livable future/MGISmart-Cities-Full-Report.ashx.

[24] Pallavi Shukla (2015). Smart Cities in India. Energy and Resource Institute. Retrieved from: http://terienvis.nic.in/WriteReadData/links/SmartCitiesin India_Report_pagewise-5937837909069130880.pdf.

[25] Pramod Kholapur (2015). Smart Cities in India Growth Drivers. Retrieved From: https://www.course5i.com/blogs/smart-cities-in-indiathe-growth-drivers/.

[26] Elmangoush, A., Coskun, H., Wahle, S. and Magedanz, T. (2013). Design aspects for a reference M2M communication platform for smart cities. 9th international conference on innovations in information technology, 204-209.

[27] Kogan, N. and Lee, K.J. (2014). Exploratory research on success factors and challenges of smart city projects. MSc Thesis, Kyung Hee University, Seoul, South Korea.

[28] Letaifa, S. B. (2015). How to strategize smart cities: Revealing the SMART model. Journal of Business Research, 68(7), 1414-1419.

[29] Komninos, N., Pallot, M., \& Schaffers, H. (2013). Special issue on smart cities and the future internet in Europe. Journal of the Knowledge Economy, 4(2), 119134.

[30] IET (2017). Smart cities - Time to involve the people. The Institution of Engineering and Technology. Available at: http://www.theiet.org/ sectors/thoughtleadership/future-cities/articles/smart-citiesinvolve. cfm?utm_source=redirect\&utm_medium=any\&utmcamp aign $=$ smartcities.

[31] Glaeser, E. L., Resseger, M., \& Tobio, K. (2009). Inequality in cities. Journal of Regional Science, 49(4), 617-646.

[32] Monzon, A. (2015). Smart cities concept and challenges: Bases for the assessment of smart city projects. International conference on smart cities and green ICT systems, 17-31

[33] Rana, N.P., Luthra, S., Mangla, S.K. Rubin Islam, Sian Roderick and Yogesh K.Dwivedi (2019). Barriers to the Development of Smart Cities in Indian Context. Information Systems Frontier ,21, 503-525.

[34] Scuotto, V., Ferraris, A., \& Bresciani, S. (2016). Internet of things: Applications and challenges in smart cities: A case study of IBM smart city projects. Business Process Management Journal, 22(2), 357-367.

[35] Vasseur, J. (2010). Smart cities and urban networks. In Vasseur, J. \& Dunkels, A. (Eds.), Interconnecting Smart Objects with IP: The Next Internet (pp. 360- 377). Burlington, MA: Morgan Kaufmann.

[36] Odendaal, N. (2003). Information and communication technology and local governance: Understanding the difference between cities in developed and emerging economies. Computers, Environment and Urban Systems, 27(6), 585-607.

[37] Smart City (2018). Driving Forces that Stimulate the 
Growth of Smart Cities. Retrieved from: https://www.smartcity.press/factors-affecting-

development-of-smart cities According to the survey analysis, development environmental pollution and sustainability. Even for the smallest cities, be the major driving force.

[38] Gil-García, J. R., \& Pardo, T. A. (2005). E-government success factors: Mapping practical tools to theoretical foundations. Government Information Quarterly, 22(2), 187-216.

[39] Scholl, H. J., Barzilai-Nahon, K., Ahn, J-H., Olga, P., \& Barbara, R. (2009). E-commerce and e-government: How do they compare? What can they learn from each other?. Proceedings of the 42nd Hawaiian International Conference on System Sciences (HICSS 2009), Koloa, Hawaii, January 4-7.

[40] William D.Eggers and John Skoworn (2018). Forces of Change: Smart Cities, Deloitte. Retrieved From: https://www2.deloitte.com/us/en/insights/focus/smartcity/overview.html.

[41] Kobayashi, A.R.K.; Kniess, C.T.; Serra, F.A.R.; Ferraz, R.R.N.; Ruiz, M.S (2017). Smart Sustainable Cities: Bibliometric Study and Patent Information. International. Journal of Innovation, 5.

[42] Neirotti, P. De Marco, A. Cagliano, A.C. Mangano, G. Scorrano, F (2014). Current Trends in Smart City Initiatives: Some Stylized Facts. Cities, 38, 25-36.

[43] Andre Luis Azevedo Guedes , Jeferson Carvalho Alvarenga, Maurício dos Santos Sgarbi Goulart, Martius Vicente Rodriguez y Rodriguez, and Carlos Alberto Pereira Soare (2018). Smart Cities: The Main Drivers for Increasing the Intelligence of Cities. Sustainability, 10,3121 .

[44] Bajaj 2018, Smart Cities in India: Creating a Smarter nation, Sterlite Tech.

[45] Cicea, Corina Marinescu and NicolaePintilie 2019, Smart cities using smart choices for energy, Theoretical and Empirical Researches in Urban Management, Vol. 14, No. 4 , pp. 22-34

[46] Enovado report 2017, The India Smart City Opportunity.

[47] Frost \& Sullivan report 2017, Smart cities.
[48] GrantThronton report 2015, Smart Cities - What's in it for Business. PHD Chamber.

[49] Gil-Garcia, J. Ramon \& Pardo, Theresa \& Nam, Taewoo. (2015). What makes a city smart? Identifying core components and proposing an integrative and comprehensive conceptualization. Information Polity. 20. 61-87. 10.3233/IP-150354.

[50] Juneja 2017, These IoT companies are helping Indian cities become smart, Your story.

[51] Kitchin R. 2016, The ethics of smart cities and urban science. Phil. Trans. R. Soc. A 374:20160115. http://dx.doi.org/10.1098/rsta.2016.0115.

[52] Market study report (2017), Smart Cities Market to 2025 by Industry Verticals (Smart Infrastructure, Smart Governance, Smart Transportations, Smart Energy and Smart Education) - Global Analysis and Forecast, The Insight Partners

[53] Pagan 2018, Smart Cities: The Next Frontier, US Black Engineer and Information Technology, Vol. 42, No. 1 (2018), pp. 78-80

[54] Research and Market report 2020, "Future of Smart Cities - Key City Profiles", Dublin.

[55] Syal and KwekuOfei-Amoh, Smart-Grid Technologies in Housing, Cityscape, Vol. 15, No. 2, Mixed Messages on Mixed Incomes (2013), pp. 283-288

[56] Smart city plans retrieved from https://economictimes.indiatimes.com/news/economy/inf rastructure/37-consulting-firms-to-prepare-smart-cityplans-for-88-cities/articleshow/49242050.cmson 16.7.2020.

[57] 100 Smart cities mission retrieved from https://smartcityhub.com/governance-economy/indias100-smart-cities-mission-is-flawed/ on 16.7.2020.

[58] Status of Smart city Projects retrieved from https://www.thehindu.com/data/what-is-the-status-ofsmart-city-projects-in-india/article28441952.ece on 16.7.2020

[59] Vanolo, A. (2014). Smart mentality: The smart city as disciplinary strategy. Urban Studies, 51(5), 883-898.

[60] Yigitcanlar, T. (2016). Technology and the city: Systems, applications and implications. New York: Routledge. 